doi:10.12662/2359-618xregea.v8i2.p31-45.2019

ARTIGOS

\title{
É POSSÍVEL SOBREVIVER A UMA RECUPERAÇÃO JUDICIAL? EVIDÊNCIAS EM EMPRESAS LISTADAS NA BM\&FBOVESPA
}

\section{SURVIVAL AFTER JUDICIAL RECOVERY? EVI- DENCE IN BRAZILIAN COMPANIES LISTED ON THE STOCK EXCHANGE}

\section{RESUMO}

A recuperação judicial tem por objetivo viabilizar a superação da situação de crise econômico-financeira da empresa, a fim de permitir a manutenção da fonte produtora, do emprego dos tra-

Sinara Jaroseski sjaroseski@ucs.br Mestra em Contabilidade e Controladoria (UNISINOS). Professora da Universidade de Caxias do Sul. Caxias do Sul - RS - BR.

Mirray Muneretto de Andrade mmandrade@ucs.br Bacharel em Ciências Contábeis pela Universidade de Caxias do Sul. Caxias do Sul - RS - BR.

\footnotetext{
Alex Eckert

alex.eckert@bol.com.br Doutor em Administração PUCRS/UCS. Professor da Universidade de Caxias do Sul. Caxias do Sul - RS - BR.

Graciela Bavaresco da Silva gracibavaresco@gmail.com Especialista em Gestão Financeira, Controladoria e Auditoria - FGV. Professora da Universidade de Caxias do Sul. Caxias do Sul - RS - BR.

Marlei Salete Mecca msmecca@ucs.br Doutora em Engenharia da Produção-UFSC. Professora da Universidade de Caxias do Sul. Caxias do Sul - RS - BR.
} balhadores e dos interesses dos credores, promovendo, assim, a preservação da empresa, sua função social e o estímulo à atividade econômica. Desse modo, a efetividade do regime de recuperação judicial é de interesse comum da sociedade. Assim, a presente pesquisa objetivou avaliar o desempenho econômico, financeiro e operacional das companhias de capital aberto, que negociam suas ações na bolsa de valores brasileira e pleitearam a recuperação judicial para superação da situação de crise econômico-financeira. A pesquisa aborda os procedimentos técnicos documentais, os levantamentos bibliográficos, com particularidades de pesquisa qualitativa e objetivos exploratórios, visando proporcionar maior familiaridade com o problema. A partir da análise dos resultados encontrados, foi possível constatar que apenas uma empresa mostrou sinais claros de recuperação da situação de crise econômico-financeira.

Palavras-chave: Análise de desempenho. Recuperação judicial. Lei 11.101/05.

\begin{abstract}
A judicial recovery has the objective to make feasible the overcoming the economic-financial crisis of the company, allow a maintenance of the source of workers' job and the interests of creditors, thus promoting a preservation of the company, its social function and stimulus to economic action. In this way, the effectiveness of the judicial recovery regime and the common interest of the company. Thus, the research aimed to evaluate the economic, financial and operational performance of publicly traded operations,
\end{abstract}


which negotiate their actions on the Brazilian stock exchange and pleaded for judicial recovery to overcome the situation of economic and financial crisis. Taking into account concepts, a research sought to analyze through the accounting indicators the effectiveness of the judicial recovery of 12 companies in the sample. From the analysis of the results found, it was possible to verify that only one company showed clear signs of recovery of the situation of economic and financial crisis.

Keywords: Performance analysis. Judicial recovery. Law 11.101/05.

\section{INTRODUÇÃO}

O presente estudo traz o resultado da análise do desempenho econômico, financeiro e operacional das empresas listadas na bolsa de valores brasileira BM\&FBOVESPA (B3) em processo de recuperação judicial, com o propósito de diagnosticar por meio dos indicadores contábeis, se o processo de recuperação no Brasil está, de fato, viabilizando a superação da situação de crise econômico-financeira. Ainda, buscou-se investigar o processo de recuperação judicial regulamentado pela Lei 11.101/05, além de fazer uma reflexão quanto à efetivação da legislação brasileira no tocante ao incentivo da atividade econômica.

O objetivo principal da presente pesquisa foi avaliar o desempenho econômico, financeiro e operacional das companhias de capital aberto, que negociam suas ações na bolsa de valores brasileira e pleitearam a recuperação judicial para superação da situação de crise econômico-financeira. Entende-se que o tema apresentado está em evidência na atual conjuntura econômica do Brasil, sendo importante seu aprofundamento para fins acadêmicos, científicos e profissionais.

De acordo com os economistas da Serasa Experian (2016), o prolongamento e a ampliação do atual quadro recessivo da economia brasileira, aliada à elevação dos custos operacionais e financeiros, tem levado empresas de pequeno a grande porte a recorrerem à recuperação judicial como instrumento para superar a crise econômico-financeira.

Conforme pesquisa do Serasa (2017), em 2016, foram protocolados 1.863 pedidos de recuperação judicial, 44,8\% a mais do que o registrado em 2015, sendo esse resultado o maior para o acumulado do ano desde 2006, quando da entrada em vigor da Lei 11.101/05, a lei brasileira que prevê a recuperação judicial e a falência de empresas.

Dessa forma, faz-se necessário analisar a efetivação desse processo para as empresas, uma vez que poucas alcançam a almejada recuperação. Nesse sentido, há a notícia publicada em 2013 pelo Jornal Estadão referente a uma análise do período de fevereiro de 2005 a outubro de 2013, em que apenas 1\% das empresas que pediram recuperação judicial no Brasil sai do processo recuperada.

Em 2016, o Jornal Estadão publicou matéria referente à dificuldade enfrentada por algumas empresas brasileiras em cumprir o plano de recuperação. De acordo com a notícia, a imprevisibilidade econômica é o argumento para a revisão dos acordos originalmente aprovados em assembleia.

Conforme o desembargador do Tribunal de Justiça de São Paulo, Carlos Henrique Abrão, a dívida das empresas que entraram em recuperação judicial soma em torno de $\mathrm{R} \$ 250$ bilhões. Desse valor, apenas $25 \%$ serão pagos efetivamente, segundo levantamento do Instituto Nacional da Recuperação Empresarial - INRE. Uma parte será reduzida durante o processo de recuperação; outra parte convertida em ações para os investidores; o restante se perde com o processo falimentar de algumas empresas (CORREÇÃO..., 2016).

Para Francisco Filho (2015), a recuperação judicial tem como meta tornar possível a superação da situação de crise econômico-financeira das empresas, permitindo que continuem produzindo, empregando trabalhadores e mantendo relações econômicas com credores. Portanto, com base na atual conjuntura econômica vislumbrada nos noticiários, faz-se ne- 
cessário um aprofundamento tanto acadêmico, como científico da presente pesquisa.

Quanto à relevância social, avaliou-se o desempenho econômico, financeiro e operacional das empresas listadas na B3, com atuação em múltiplas áreas da economia, e de grande relevância no cenário econômico brasileiro.

A presente pesquisa visa corroborar o conhecimento acerca da execução da legislação quanto à recuperação judicial, no tocante ao incentivo da atividade econômica. Neste sentido, Salomão e Santos (2015) afirma que a Lei 11.101/05, que regulamenta a recuperação judicial, foi inspirada em ditames de ordem constitucional, como o princípio da função social da propriedade e a diretriz segundo a qual o Estado, como agente regulador e normativo, exerce incentivo da atividade econômica, na forma da Lei.

\section{REFERENCIAL TEÓRICO}

\subsection{DEMONSTRAÇÕES CONTÁBEIS}

Viceconti e Neves (2013) conceitua a Contabilidade como uma ciência que desenvolveu metodologia própria, com a finalidade de controlar o patrimônio das entidades, apurar o resultado e prestar informações às pessoas que tenham interesse na avaliação da situação patrimonial. Para Quintana (2014), a Contabilidade pode ser definida como a ciência social que registra as transações ocorridas em uma entidade, com a finalidade de resumir esses fatos em demonstrações que possam expressar a situação patrimonial, com o objetivo principal de gerar informações que contribuam para a tomada de decisões.

O Código Civil Brasileiro, por meio da Lei 10.406/02 (BRASIL, 2002), regulamenta que todas as instituições têm obrigatoriedade de escrituração contábil e elaboração de demonstrações contábeis. Dos inúmeros relatórios preparados com base em informações contábeis, destacam-se aqueles que são obrigatórios, de acordo com a legislação brasileira, elencados na Lei $n^{\circ}$ 6.404/76 (BRASIL, 1976), alterada pelas Leis $\mathrm{n}^{\mathrm{o}} 11.638 / 2007$ (BRASIL, 2007) e 11.941/2009 (BRASIL, 2009):
a) balanço patrimonial (BP);
b) demonstração do resultado do exercí- cio (DRE);
c) demonstração de lucros ou prejuízos acumulados (DLPA);
d) demonstração das mutações do patri- mônio líquido (DMPL);
e) demonstração dos fluxos de caixa (DFC);
f) demonstração do valor adiciona- do (DVA), apenas para companhias abertas;
g) notas explicativas às demonstrações contábeis (NE).

De acordo com Eckert (2013), as demonstrações contábeis evidenciam diferentes informações provenientes da contabilidade das empresas, servindo aos mais diferentes usuários das informações, sejam estes internos ou externos.

\subsection{ANÁLISE DAS DEMONSTRA- ÇÕES CONTÁBEIS}

A análise das demonstrações contábeis, de acordo com Lins e Francisco Filho (2012), assume destacada importância no processo decisório, constituindo-se em um relevante instrumento de avaliação de desempenho, oferecendo indicadores das perspectivas econômicas, financeiras e operacionais da empresa.

Silva (2012) descreve que, a partir dos relatórios contábeis, é possível avaliar o comportamento da gestão, realizar comparações com as tendências regionais ou dos segmentos, determinando as perspectivas futuras de rentabilidade ou continuidade dos negócios. Essas informações oferecem subsídios aos gestores em sua tomada de decisão quanto a financiamentos ou investimentos, na avaliação de mudanças de práticas, caso as tendências não sejam favoráveis.

De acordo com Silva (2012), para a análise das demonstrações contábeis, podem-se utilizar várias metodologias, de acordo com os 
objetivos a serem alcançados, tais como análise horizontal, análise vertical, análise por meio de índices ou quocientes e outras metodologias complementares.

A presente pesquisa aborda uma série de indicadores ou quocientes a serem apurados por meio da relação entre contas ou grupos de contas que integram as demonstrações contábeis das empresas objeto de estudo. No Quadro 1, está descrita a correlação entre as informações abordadas e os grupos de índices analisados.

Quadro 1 - Correlação dos segmentos abordados x Indicadores contábeis

Informações

\begin{tabular}{|c|}
\hline Situação financeira \\
\hline Situação econômica \\
\hline Situação operacional \\
\hline
\end{tabular}

Grupos de Índices

\begin{tabular}{|c|}
\hline Liquidez \\
\hline Estrutura de capital \\
\hline Rentabilidade \\
\hline Rotação/Prazos médios \\
\hline Alavancagem operacional \\
\hline
\end{tabular}

Fonte: (MONTOTO, 2014, p. 931).

\subsection{INDICADORES DE ROTATIVIDADE/ATIVIDADE (PRAZOS MÉDIOS)}

Lins e Francisco Filho (2012) afirmam que os indicadores de atividade, obtidos a partir de dados extraídos do Balanço Patrimonial e da Demonstração do Resultado do Exercício, evidenciam a velocidade com que determinados elementos do ativo e do passivo giram, ou ainda se renovam, durante o período contábil.

No Quadro 2, apresentam-se os índices de atividade, as fórmulas, as definições e as avaliações elencados por Saporito (2015).

Quadro 2 - Índices de atividade

\begin{tabular}{|c|c|c|}
\hline Índice & Fórmula & \multirow{3}{*}{$\begin{array}{l}\text { Significado e Avaliação } \\
\text { Indica o tempo estimado para o } \\
\text { recebimento das vendas, ou seja, por } \\
\text { quanto tempo, em média, a empresa } \\
\text { financia seus clientes. A resposta é obtida } \\
\text { em número de dias. Quanto menor o } \\
\text { PMRV, melhor. }\end{array}$} \\
\hline \multirow[t]{2}{*}{$\begin{array}{c}\text { Prazo Médio do Recebimento } \\
\text { de Vendas (PMRV) }\end{array}$} & $\underline{\text { Clientes x } 360}$ & \\
\hline & Vendas & \\
\hline \multirow{2}{*}{$\begin{array}{l}\text { Prazo Médio da Renovação de } \\
\text { Estoques (PMRE) }\end{array}$} & Estoques x 360 & \multirow{2}{*}{$\begin{array}{l}\text { Indica o tempo estimado necessário para } \\
\text { que a empresa renove seus estoques. A } \\
\text { resposta é obtida em número de dias. } \\
\text { Quanto menor o PMRE, melhor. }\end{array}$} \\
\hline & $\mathrm{CPV}$ & \\
\hline \multirow{2}{*}{$\begin{array}{l}\text { Prazo Médio do Pagamento de } \\
\text { Compras (PMPC) }\end{array}$} & Fornecedores x 360 & \multirow{2}{*}{$\begin{array}{l}\text { Indica o tempo estimado para o } \\
\text { pagamento de compras, ou seja, por } \\
\text { quanto tempo, em média, a empresa } \\
\text { é financiada por seus fornecedores. A } \\
\text { resposta é obtida em números de dias. } \\
\text { Quanto maior o PMPC, melhor. }\end{array}$} \\
\hline & Compras & \\
\hline
\end{tabular}

Fonte: adaptado pelos autores deste trabalho com base em Saporito (2015, p. 195). 


\subsubsection{Ciclo operacional $x$ ciclo financeiro}

Assaf Neto (2010) descreve que as empresas na consecução de suas atividades operacionais, sistematicamente, produzem bens ou serviços, vende-os para, posteriormente, obter os valores referentes a seu pagamento, com o intuito de obter lucros, para que possam satisfazer às expectativas de retorno de suas fontes de financiamento.

Segundo Silva (2012), cada empresa possui um ciclo operacional próprio, sendo assim, um período de tempo necessário para desenvolver suas atividades, tais como a aquisição de mercadorias ou matéria-prima, a estocagem, a produção, a distribuição e o recebimento do valor correspondente às suas vendas. De acordo com Matarazzo (2010), os índices de prazos médios avaliados em conjunto resultarão na análise do ciclo operacional e de caixa, os quais se caracterizam como elementos que indicam o fracasso ou o sucesso de uma empresa.

O ciclo de caixa é determinado, basicamente, pela diferença entre o número de dias do ciclo operacional e o prazo médio de pagamento a fornecedores dos insumos (ASSAF NETO, 2010). Para Padoveze e Benedicto (2011), o acompanhamento rotineiro dos ciclos é importante, pois permite o gerenciamento do capital de giro e aponta a necessidade de investimento em ativos, possibilitando, assim, "uma visão muito expressiva do andamento das operações da empresa e o seu impacto financeiro e patrimonial." (PADOVEZE; BENEDICTO, 2011, p. 174).

\subsection{INDICADORES DE LIQUIDEZ}

Gitman e Zutter (2010) ressaltam a importância de mensurar a liquidez, relacionada à solvência das entidades, demostrando o grau de capacidade da empresa em pagar suas dívidas. Padoveze e Benedicto (2011) explicam que liquidez em finanças denota disponibilidade em moeda corrente para fazer pagamentos, ou seja, extinguir obrigações. Desse modo, os indicadores de liquidez mensuram se, de fato, os bens e os direitos da empresa (ativos) são suficientes para a liquidação/extinção de suas dívidas (passivos).

Padoveze e Benedicto (2011) ressaltam que os indicadores de liquidez são considerados estáticos, pois são extraídos do balanço patrimonial. Assim, cabe ao analista avaliar "quais as possibilidades futuras da empresa de gerar novos lucros, aumentar ou diminuir seus ativos realizáveis e aumentar ou diminuir seus passivos exigíveis." (PADOVEZE; BENEDICTO, 2011, p. 148).

\subsection{INDICADORES DA ESTRUTURA DE CAPITAL (ENDIVIDAMENTO)}

Braga (2012) afirma que as empresas possuem um limite de endividamento, que está, proporcionalmente, ligado à capacidade de gerar recursos necessários para o pagamento de suas obrigações dentro dos prazos estipulados.

Silva (2012) complementa afirmando que os indicadores da estrutura de capital, além de conexos à composição dos capitais (próprios ou de terceiros), apontam os níveis de imobilização de recursos, que buscam apontar diversas relações na composição da dívida da empresa.

\subsection{INDICADORES DE RENTABILIDADE}

Para Padoveze e Benedicto (2011), a análise da rentabilidade objetiva aponta o retorno do capital investido, bem como os fatores que conduzem a essa remuneração. A saúde financeira da empresa é decorrente da obtenção de sua rentabilidade. Assim, uma empresa rentável e adequadamente administrada não terá problemas de solvência ou capacidade de pagamento. Segundo Griffin (2012), os indicadores de rentabilidade mensuram a capacidade da empresa de gerar lucros e aponta a eficácia da aplicação dos recursos investidos na empresa.

Assaf Neto (2010) afirma que o risco de inadimplência das empresas é estudado a partir do potencial da geração de fluxos de caixa decorrentes de suas operações. Assim, quanto maior a capacidade de geração de caixas de uma empresa, mais segura será sua capacidade de pagamento; por conseguinte, promove uma redução em seu risco de inadimplência. 


\subsection{RECUPERAÇÃO JUDICIAL}

Martins (2016) conceitua a Recuperação Judicial como um procedimento corretivo em que se objetiva reestruturar e recuperar uma atividade empresarial em crise, mantendo a fonte de produção de emprego, atendendo aos interesses dos credores e garantindo a preservação da função social da empresa.

Para Carter e Van Auken (2006), o escopo envolvido em um processo de recuperação judicial geralmente está centrado na falta de conhecimento sobre gerenciamento, precificação e equivocadas projeções futuras. Adicionalmente, mencionam que o clima econômico externo tem ligação com o insucesso de um negócio, representado por dificuldades relacionadas aos clientes, à economia e aos concorrentes.

O instrumento de recuperação judicial, previsto na Lei $n^{0} 11.101$ de 2005 (BRASIL, 2005), conhecida como "Lei de recuperação judicial e falência de empresas", tem os objetivos de proteger a atividade da empresa, manter o emprego dos trabalhadores e os interesses dos credores.

No art. 50 do instrumento legal que regulamenta a recuperação judicial, estão elencados alguns exemplos de medidas que podem ser utilizados como forma de superar a crise, assim sumarizados por Toledo e Abrão (2012):

Sistematizando-os, pode-se classificá-lós em meios de reestruturação: a) do poder de controle; b) financeira; c) econômica; d) administrativa; e) societária; e f) complexa ou híbrida ou mista, que a LRE instituiu com o "objetivo de viabilizar a superação da situação de crise econômico-financeira do devedor" (art. 47), uns empregados diretamente na empresa, outros, em sua controladora, sobrelevando notar, desde logo, que, em geral, será importante utilizar vários meios de recuperação ao mesmo tempo para alcançar a salvação da empresa (TOLEDO; ABRÃO, 2012, p. 190).

Alguns benefícios podem ser alcançados pelas empresas que optam em ingressar em um processo de recuperação judicial, já que a Lei 11.101 de 2005 (BRASIL, 2005) prevê, após a deferimento do pedido de recuperação judicial junto ao Poder Judiciário, a concessão de prazos e condições especiais para o pagamento de obrigações, mediante o cumprimento de ações de reestruturação da empresa.

De acordo com Fazzio Júnior (2015), o plano de recuperação judicial, além de descrever as medidas necessárias e oportunas para superação da situação de crise do devedor, deve ser condicionado ao interesse social, assim atendendo ao interesse dos seus credores.

\subsubsection{Plano de recuperação}

Conforme descrito por Ayoub e Cavalli (2016), o plano de recuperação judicial deverá conter a descrição detalhada dos meios de recuperação, a demonstração da viabilidade econômica da atividade, o laudo econômico-financeiro e o laudo de avaliação dos bens e ativos do devedor.

Para Mamede (2016), o plano de recuperação é o elemento chave para a superação da situação de crise da empresa: "é o projeto e o caminho que o devedor propõe aos credores para sair da situação caótica, deficitária, e chegar a um estado saudável da atividade negocial." (MAMEDE, 2016, on-line).

\subsubsection{Credores inclú́dos na recuperação judicial}

Estão sujeitos ao plano de recuperação judicial, nos termos da Lei 11.101/05 (BRASIL, 2005), credores trabalhistas ou por acidentes de trabalho; credores com garantia real; credores enquadrados como microempresas ou empresas de pequeno porte, além dos credores quirografários, com privilégio especial, geral, ou subordinados.

Importa mencionar que, para os credores da espécie trabalhista, há regras específicas para a negociação de seus créditos, definidas nos termos do art. 54. da Lei 11.101/05 (BRASIL, 2005). Em síntese, o referido artigo dispõe que o plano de recuperação judicial não poderá prever prazo superior a um ano para pagamento 
dos créditos derivados da legislação do trabalho, bem como prazo superior a trinta dias para o pagamento das verbas estritamente salariais, referentes aos três últimos meses, limitadas a cinco salários mínimos por trabalhador.

\subsection{3 Órgãos previstos pela Lei}

Segundo Abrão e Toledo (2016), ao juiz é dada a função de presidir o processo jurídico, ao Ministério Público, a função de atuar como fiscal da Lei, em nome do interesse coletivo. Assim, no desempenho de suas funções, tanto o magistrado, quanto o membro do Ministério Público terão a participação dos seguintes órgãos ou auxiliadores: administrador judicial, o comitê de credores e a assembleia geral de credores.

a) administrador judicial: poderá ser pessoa física ou jurídica, que dispõe de condições técnicas para auxiliar no processo, preferencialmente, advogados, economistas, administradores de empresas ou contadores;

b) comitê de credores: órgão de representação, criado para acompanhar o cotidiano do procedimento jurídico de recuperação judicial, com atribuições consultivas e fiscalizatórias, o qual deverá ser composto por representantes das classes de credores;

c) assembleia geral de credores: órgão que agrega todos aqueles que têm créditos contra a sociedade empresária. Sua principal função é apreciar o plano de recuperação judicial, com o intuito de aprovar, modificar ou ainda rejeitar o mesmo.

\subsubsection{Processo de recuperação judicial}

Descritos os requisitos, as formas de recuperação, bem como os órgãos que fazem parte desse processo, passa-se a apresentar como esses pilares se integram durante o processo de recuperação judicial. Para Coelho (2014), esse procedimento pode ser descrito em três fases: a postulatória, a deliberativa e a executória.

Para esse autor, a fase denominada con- siste no requerimento do benefício por parte do empresário ou sociedade empresária, na forma da petição inicial e termina com o despacho do juiz, deferindo o prosseguimento do pedido. Nesta etapa, tem-se como objetivo a verificação da presença dos requisitos formais da recuperação.

Na segunda fase, descrita por Coelho (2014) como deliberativa, são verificados os créditos envolvidos no processo, em que os credores atingidos discutem e aprovam o plano de recuperação, tendo como início o despacho de prosseguimento, e, como encerramento, a decisão concessiva do benefício.

Por fim, a fase de execução compreende o período de cumprimento do plano de recuperação, bem como a fiscalização por parte dos órgãos ou dos auxiliadores. Essa fase parte da decisão concessiva do benefício e é concluída pela sentença de encerramento.

De acordo com Salomão (2015), após mais de dez anos de vigência da Lei 11.101/05 (BRASIL, 2005), serão necessários mais alguns anos para que a jurisprudência e a doutrina se posicionem sobre algumas questões, o que vem de encontro com os objetivos da presente pesquisa, que consistem em avaliar o desempenho das companhias de capital aberto listadas na B3 que pleitearam o processo de recuperação judicial para superação da situação de crise econômico-financeira, com vistas a verificar a efetividade da Lei 11.101/05, como forma de incentivo à atividade econômica.

\subsubsection{Contexto internacional}

Roberts et al. (2010) apontam que, na Espanha, os legisladores espanhóis aprovaram um conjunto de decretos e leis reais (geralmente conhecidos como Plano E) para estimular uma economia fraca. Esses decretos contêm, em suas orientações e textos, medidas urgentes de legislação tributária, financeira e de falências que se adaptam ao desenvolvimento da situação econômica atual do país. Essas ações vão de encontro com a estabilização dos mercados financeiros, oferecendo às empresas com problemas de liquidez um acesso mais fácil ao dinheiro. 
Nota-se, também, que desde a aprovação dessas leis e decretos, vários acórdãos assinalaram as suas insuficiências, cujo objetivo é reduzir os custos processuais, facilitar o refinanciamento de empresas viáveis, melhorar a situação jurídica dos trabalhadores afetados pela falência ou recuperação judicial da sua empresa, estimular acordos antecipados com credores e expandir os procedimentos acelerados a empresas com responsabilidades inferiores a 10 milhões de euros.

A legislação de insolvência russa mudou, dramaticamente, desde 1992, quando a primeira lei foi adotada. As primeiras disposições em matéria de insolvência tinham, essencialmente, natureza declarativa e aplicação prática mínima. Desde então, o foco da legislação de insolvência russa mudou, significativamente, para proteger os interesses dos credores e para estabelecer um equilíbrio entre os interesses destes e seus devedores. Uma das alterações mais significativas diz respeito aos procedimentos simplificados para iniciar a falência/recuperação. Anteriormente, os credores podiam apresentar uma petição a um tribunal por declarar um devedor falido ao término de trinta dias após a entrega de um mandado de execução para o serviço judicial e uma cópia para o devedor. As alterações permitem aos credores apresentar um pedido a partir da data de entrada de uma decisão judicial contra o devedor.

\section{MÉTODO DE PESQUISA}

\subsection{CARACTERIZAÇÃO DA PESQUISA}

Para a realização da presente pesquisa, utilizou-se de procedimentos técnicos documentais e de levantamento, além de uma pesquisa bibliográfica.

Pereira (2012) argumenta que a pesquisa documental tem por finalidade reunir, classificar e distribuir os documentos de todo gênero dos diferentes domínios da atividade humana. Assim, os dados da presente pesquisa foram elaborados a partir de materiais que não receberam tratamento analítico, tais como notícias, demonstrações contábeis das empresas pesquisadas, relató- rios, dados estatísticos, entre outros relacionados à recuperação judicial. Para atingir os objetivos propostos, buscou recolher um grande número de dados dos processos de recuperação judicial das empresas no período delimitado.

Quanto ao levantamento, Siqueira (2013) afirma que esse método busca realizar uma descrição, relato ou levantamento dos fenômenos, seguido de interpretação. Portanto, buscaram-se pesquisar as empresas em situação de dificuldades econômico-financeiras, listadas na B3, com o propósito de avaliá-las nos aspectos econômico, financeiro e operacional, a fim de apontar as dificuldades do processo de recuperação judicial regulamentado no Brasil diante dos casos analisados.

A pesquisa bibliográfica busca o levantamento bibliográfico sobre o tema, com o propósito de identificar informações e subsídios para definição dos objetivos, determinação do problema e definição dos tópicos do referencial teórico (MICHEL, 2015). Logo, as descobertas e as constatações foram elaboradas a partir de materiais já publicados, constituídos por livros, artigos de periódicos, entre outros que se relacionam com os processos de recuperação judicial das empresas escolhidas para o estudo.

Da abordagem do problema, trata-se de uma pesquisa qualitativa, descrita por Pereira (2012) como aquela que pode trazer a interpretação dos fenômenos e a atribuição de significados.

Do ponto de vista dos objetivos, a pesquisa caracteriza-se por exploratória, pois, de acordo com Ramos (2009), esse modelo visa proporcionar maior familiaridade com o problema, tornando-o explícito. Levando-se em consideração esses aspectos, analisou-se o desempenho econômico, financeiro e operacional das empresas com processo de recuperação judicial, listadas na B3 até dezembro de 2016.

\subsection{POPULAÇÃO E AMOSTRA}

Akanime e Yamamoto (2013) definem população como a totalidade de indivíduos ou objetos que possuem ao menos uma característica em comum, sendo o subconjunto de uma população, a amostra. Para Mascarenhas 
(2012), a amostra é caracterizada por um pedaço da população que se pretende pesquisar. Portanto, a população desta pesquisa abrange as 24 empresas listadas na B3 até dezembro de 2016 com processo de recuperação judicial ativo.

A amostra é composta por doze companhias, com registro regular na bolsa de valores brasileira, devidamente aptas a desenvolver suas atividades operacionais; empresas com processo falimentar foram excluídas. Para a seleção da amostra, foi levada em consideração também a data de aprovação do plano de reestruturação - foram eliminadas as companhias com plano de recuperação aprovado em assembleia geral de credores apenas em 2016, pois pretende-se verificar a efetividade do processo de recuperação judicial, e, nesses casos, os dados para embasamento da pesquisa seriam escassos.

O Quadro 3 demonstra a relação de empresas que serviram de amostra para esta pesquisa.

Quadro 3 - Amostra de companhias em recuperação judicial listadas na B3

\begin{tabular}{|c|c|c|c|}
\hline Empresa & Fundação & Sede & Atividade principal \\
\hline $\begin{array}{l}\text { Companhia Industrial } \\
\text { Schlosser S.A }\end{array}$ & 17/8/1966 & Brusque (SC) & $\begin{array}{l}\text { Produção e comercialização de produtos } \\
\text { têxteis. }\end{array}$ \\
\hline $\begin{array}{l}\text { Fibam Cia Industrial } \\
\text { S.A }\end{array}$ & $26 / 10 / 1970$ & $\begin{array}{l}\text { São Bernardo do } \\
\text { Campo (SP) }\end{array}$ & $\begin{array}{l}\text { Fabricação de peças e acessórios para veículos } \\
\text { automotores. }\end{array}$ \\
\hline $\begin{array}{l}\text { Inepar Equipamentos } \\
\text { e Montagens S.A }\end{array}$ & $31 / 10 / 1997$ & São Paulo (SP), & $\begin{array}{l}\text { Fabricação e fornecimento de bens de capital } \\
\text { sob encomenda, sistemas em regime "Turn- } \\
\text { Key" (Pacotes). }\end{array}$ \\
\hline $\begin{array}{l}\text { Inepar S.A Indústria e } \\
\text { Construções }\end{array}$ & 20/12/1971 & São Paulo (SP) & $\begin{array}{l}\text { Fabricação de equipamentos e sistemas } \\
\text { elétricos, de torres e acessórios para } \\
\text { transmissão de energia e telecomunicações. }\end{array}$ \\
\hline $\begin{array}{l}\text { Kosmos Comércio de } \\
\text { Vestuários S.A }\end{array}$ & 05/12/1994 & São Paulo (SP) & $\begin{array}{l}\text { Comércio por atacado e varejo, desenvolvido } \\
\text { em lojas e magazines. }\end{array}$ \\
\hline $\begin{array}{l}\text { Mangels Industrial } \\
\text { S.A }\end{array}$ & 06/7/1966 & $\begin{array}{l}\text { São Bernardo do } \\
\text { Campo (SP) }\end{array}$ & $\begin{array}{l}\text { Produção e venda de rodas automotivas de } \\
\text { alumínio, de recipientes de Gás Liquefeito de } \\
\text { Petróleo (GLP) para ônibus e caminhões. }\end{array}$ \\
\hline $\begin{array}{l}\text { OGX Petróleo e Gás } \\
\text { S.A }\end{array}$ & $27 / 6 / 2007$ & $\begin{array}{l}\text { Rio de Janeiro } \\
\qquad(\mathrm{RJ})\end{array}$ & $\begin{array}{l}\text { Pesquisa, lavra, refino, processamento, } \\
\text { comércio e transporte de petróleo e gás natural } \\
\text { e de outros hidrocarbonetos, e atividades } \\
\text { correlatas. }\end{array}$ \\
\hline $\begin{array}{c}\text { Óleo e Gás } \\
\text { Participações S.A }\end{array}$ & $10 / 4 / 2006$ & $\begin{array}{l}\text { Rio de Janeiro } \\
\qquad(\mathrm{RJ})\end{array}$ & $\begin{array}{l}\text { Participação no capital de outras sociedades, } \\
\text { que atuam no segmento de petróleo e gás, } \\
\text { nacionais ou estrangeiras, constituídas sob } \\
\text { qualquer tipo societário. }\end{array}$ \\
\hline OSX Brasil S.A & 03/9/2007 & $\begin{array}{l}\text { Rio de Janeiro } \\
\qquad(\mathrm{RJ})\end{array}$ & $\begin{array}{l}\text { Participação no capital social de outras } \\
\text { sociedades, dedicadas ao setor de } \\
\text { equipamentos e serviços para a indústria } \\
\text { offshore de óleo e gás natural, com atuação } \\
\text { integrada nos segmentos de construção naval. }\end{array}$ \\
\hline Rede Energia S.A & $17 / 8 / 1966$ & São Paulo (SP) & $\begin{array}{l}\text { Participação no capital de outras empresas, } \\
\text { tendo como base a atividade de distribuição } \\
\text { e geração de energia elétrica, e atividades } \\
\text { correlatas. }\end{array}$ \\
\hline
\end{tabular}




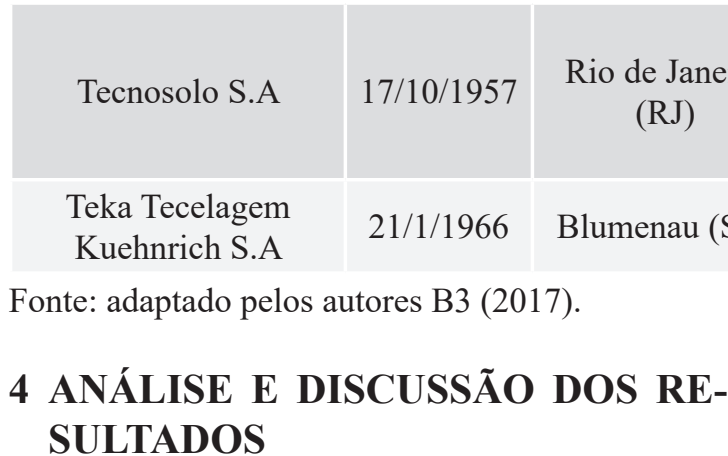

Para a realização desta pesquisa, optou-se em analisar as demonstrações contábeis das empresas, compreendendo o ano antes do pedido de recuperação judicial e todos os anos posteriores ao pedido. Para tanto, foram calculados os indicadores contábeis contemplados na pesquisa por meio de planilha eletrônica, com base nas demonstrações contábeis das companhias, obtidas por meio de download no site da B3.

Partindo da premissa de que a finalidade da análise das demonstrações contábeis é de fornecer bases para inferir o que poderá acontecer no futuro e identificar tendências para tomadas de decisões, a pesquisa traz a análise dos indicadores que apontam a situação econômica, financeira e operacional das companhias listadas na B3, com processo de recuperação judicial, a fim de contribuir com a verificação do desempenho desse incentivo à atividade econômica.

Partindo da análise das demonstrações financeiras das empresas abrangidas na amostra, a pesquisa buscou investigar o processo de recuperação judicial, quanto a seu objetivo de viabilizar a superação da situação de crise econômico-financeira.

Outras informações econômicas e financeiras, relacionadas ao processo de recuperação judicial, foram extraídas dos Relatórios de Auditoria, além de informações adicionais disponibilizadas no site da Comissão de Valores Mobiliários - CVM.

De fato, a amostra objeto da pesquisa abrange empresas em crise econômico-financeira, as quais vêm enfrentando dificuldades recorrentes da atividade produtiva, como hiperinflação, congelamento de preços, variações
Atividades ligadas à mecânica de solos, sondagens, fundações e contenções de encostas, controle tecnológico de qualidade e construção civil.

Produção e comercialização de produtos têxteis. cambiais e abruptas oscilações de juros praticados no mercado financeiro, além de outros fatores pontuais, que levaram todas essas empresas a se socorrerem na possibilidade da recuperação judicial. Por exemplo, as empresas voltadas para o setor têxtil e de vestuário, que enfrentaram problemas com a redução do faturamento em função da concorrência externa; a dificuldade de adaptação do custo fixo à nova realidade mercadológica; a corrosão do capital próprio em decorrência do acúmulo de resultados econômicos negativos e consequentes aumentos do endividamento e redução da capacidade de pagamento; a dificuldade de acesso às fontes de financiamentos, pela total ausência de crédito e a alta do preço de suas principais matérias primas.

As empresas do setor metal mecânico e automobilístico sofrem com o reflexo da crise mundial desde 2008, iniciada na Europa e nos Estados Unidos. Embora o governo brasileiro tenha auxiliado o setor com medidas que buscavam minimizar o impacto da crise econômica, como o Programa Inovar-Auto, visando reduzir os impostos para o setor automobilístico, essas benesses não foram suficientes para alavancar as vendas de veículos, tendo em vista a falta de crédito e a confiança do consumidor, razão pela qual a situação econômica das empresas do segmento agravou-se gradativamente nos anos posteriores.

Dos fatores pontuais que levaram as empresas de energia à situação de crise econômico-financeira, pode-se citar a complexidade do setor energético brasileiro, que, desde 1995, vem passando por profundas transformações. A edição de leis e regulamentos vem sendo instituída em relação ao regime de concessão, à operacionalização de revisões tarifárias, à co- 
mercialização de energia, às regras para atendimento aos consumidores cativos e livres, e também à criação de novos agentes institucionais, além daqueles já existentes.

Das empresas voltadas para o setor de infraestrutura, bem como para o setor petrolífero, as principais causas da instaurada crise econômico-financeira são a recessão da economia, os vultosos resultados negativos de projetos frustrados de extração de óleo e gás, que, embora a investigação técnica empreendida inicialmente tenha resultado em previsões de produção significativas, a exploração mostrou-se comercialmente inviável em alguns casos, além das questões políticas relacionadas às investigações na empresa Petrobras.

Depois de constatada a crise econômico-financeira, as empresas abrangidas na amostra concluíram que a recuperação judicial lhes proporcionaria mecanismos para viabilizar a superação da situação de crise econômico-financeira. Os objetivos para tanto permeiam a necessidade de equilibrar o interesse social, a satisfação dos credores e o respeito aos direitos do devedor, promovendo, assim, a preservação da empresa, sua função social e o estímulo à atividade econômica.

De acordo com decisões do Superior Tribunal de Justiça - STF, após cumpridas as exigências legais da Lei 11.101/05 (BRASIL, 2005), o juiz deve conceder a recuperação judicial do devedor, cujo plano tenha sido aprovado em assembleia geral dos credores, pois não cabe a este julgar quanto ao aspecto da viabilidade econômica da empresa, uma vez que tal questão é de exclusiva apreciação dos credores.

Das empresas abrangidas na amostra, $75 \%$ aguardaram mais de seis meses para ter seu plano de recuperação judicial aprovado pela assembleia geral dos credores, havendo casos em que esse prazo chegou próximo a dois anos. Ou seja, em média, as empresas ficaram um semestre sem o efetivo pagamento aos credores, além de gozarem de privilégios para o pagamento de suas dívidas, por meio de prazos estendidos com deságio sobre estes, emissão de debêntures perpétuas, entre outros.
Da análise econômica e financeira das empresas citadas na pesquisa, pode-se concluir que prazos estendidos para o pagamento de passivos, embora bastante favoráveis em um primeiro momento, podem não ser suficientes se não houver aumento no faturamento e na redução nos custos e ainda podem dar a ideia de que a empresa esteja trabalhando com prazos alongados para pagamento de suas dívidas, quando, na verdade, estas estão em atraso por falta do cumprimento da obrigação. Empresas em recuperação judicial precisam se tornar capazes de obter rentabilidade sobre os ativos investidos, produzindo efeito, ao longo dos anos, sobre a liquidez, bem como um bom posicionamento do endividamento, de modo a rentabilizar o acionista e não onerar a atividade com o custo financeiro dessa operação.

Portanto, ainda que a renegociação da dívida com prazos estendidos seja um ponto positivo da recuperação judicial, deve-se ter cautela com esse mecanismo, conforme as circunstâncias já mencionadas.

Outro ponto que deve ser analisado refere-se ao crédito tributário, considerado um grande problema para as empresas que buscam sua recuperação. Como é de conhecimento, a Lei 11.101/05 (BRASIL, 2005), que dispõe sobre a recuperação judicial, entrou em vigor em 8 de junho de 2005. Todavia, somente ao final do ano de 2014, foi instituído parcelamento de dívidas fiscais no âmbito federal, especialmente para as sociedades em recuperação judicial, regulamentado pela Lei 13.043/2014.

$\mathrm{O}$ que poderia ser considerado um ponto positivo, todavia, em linha de princípio, este parcelamento não representa um direito, propriamente dito, para o contribuinte, tendo em vista que a possibilidade de parcelamento está subordinada a condições onerosas para a sociedade em recuperação, em desacordo com o princípio da preservação da empresa. Neste ponto, cabe mencionar que compete ao judiciário equilibrar os interesses em conflito, notadamente entre a reestruturação pretendida pela empresa que busca a recuperação (empregos, aquecimento econômico) e o interesse público 
para recebimento dos tributos devidos (saúde, educação, segurança, por exemplo).

De fato, o instituto da recuperação judicial possibilita às empresas em crise econômico-financeira diversas formas para se recuperar, todavia, de acordo com os dados desta pesquisa, verifica-se que esse processo é longo, sendo assim, necessária a revisão das medidas inicialmente assentidas no plano de recuperação. Ainda que aprovada a viabilidade econômica das empresas por seus credores, há outros fatores que influenciam sua recuperação. Por exemplo, a queda do faturamento é um fator mercadológico imprevisível que prejudicou e ainda prejudica a recuperação de muitas empresas.

Das análises abordadas, constata-se que apenas a empresa Rede Energia apontou resultados satisfatórios para concluir que está em via de se recuperar, enquanto as demais continuam trabalhando com um ciclo financeiro desfavorável, má estrutura do endividamento e baixa rentabilidade sobre os ativos.

Em agosto de 2016, a Rede de Energia obteve decisão decretando o encerramento da recuperação judicial, uma vez que cumpriu todas as obrigações previstas no plano de recuperação dentro do período de dois anos, conforme disposto no artigo 61, da Lei 11.101/2005 (BRASIL, 2005). Contra essa decisão, alguns credores apresentaram embargos de declaração, os quais foram devidamente rejeitados pelo juízo da recuperação em decisão datada de 11/10/2016. Na sequência, um dos credores da companhia interpôs apelação contra a decisão de encerramento. Aguarda-se o processamento do recurso e o seu julgamento pelo Tribunal de Justiça de São Paulo.

Do mesmo modo, a empresa Mangels S.A teve decretado o fim do acompanhamento judicial sobre sua recuperação em março de 2017. Todavia, o encerramento da recuperação judicial ocorreu três meses depois de a Mangels ter aprovado um aditivo alterando as condições de pagamento estabelecidas no plano inicial, aumentando a carência para mais dois anos dos pagamentos das dívidas repactuadas, a fim de possibilitar melhor redistribuição e equilíbrio no fluxo de pagamento da dívida durante o período. Conforme os indicadores abordados na pesquisa, a empresa ainda não emitia sinais claros de recuperação. Cabe mencionar que o fim do acompanhamento judicial não restringirá a duração do plano, o qual deverá perdurar o tempo descrito e aprovado na assembleia geral dos credores.

Outro ponto a se destacar é o fato de que essas empresas, ao longo de suas dificuldades enfrentadas na esfera econômica e financeira, foram perdendo a credibilidade junto a seus credores. Como o objetivo é recuperar a atividade, muitas vezes elas esbarram na falta de crédito, prazos e fornecimento para assegurar sua continuidade.

De acordo com a Lei 11.101/05 (BRASIL, 2005), a recuperação judicial deve ser um incentivo à atividade econômica, entretanto, diante dos casos analisados, entende-se que a lei deve ser revista para que esse procedimento seja rápido e eficaz para as grandes companhias do País. O grande objetivo dessa regulamentação é viabilizar a superação da situação de crise econômico-financeira do devedor, a fim de permitir a manutenção da fonte produtora, do emprego dos trabalhadores e dos interesses dos credores, promovendo, assim, a preservação da empresa, sua função social e o estímulo à atividade econômica.

\section{CONSIDERAÇÕES FINAIS}

O peculiar quadro atual da economia brasileira demanda cautela para toda a sociedade. É notório como o mercado de capitais reage a cada notícia fornecida pela mídia, que, consequentemente, afeta a inflação, restringe os investimentos e faz que o dólar oscile. Enfim, uma série de fatores que, implacavelmente, afetam a economia brasileira.

Diante disso, a pesquisa buscou abordar aspectos relevantes da recuperação judicial, com a finalidade de apontar, por meio dos indicadores contábeis, o desempenho das empresas que recorreram a esse procedimento jurídico, como forma de viabilizar a superação da situação de crise econômico-financeira. 
De fato, a recuperação judicial proporciona diversos meios que podem ser utilizados pelas empresas para superar a situação de crise. Todavia, diante dos casos analisados na pesquisa, pode-se concluir que apenas uma empresa teve sinais claros de recuperação, e ainda assim, aguarda o desfecho de procedimentos jurídicos, para então obter o fim do acompanhamento judicial sobre sua atividade econômica.

A Lei 11.101/05 (BRASIL, 2005), que regulamenta a recuperação judicial no Brasil, possui vários pontos positivos e negativos para as empresas que recorrem a esse procedimento jurídico. Assim, cabe aos gestores avaliar se, de fato, esse procedimento irá reestruturar seu negócio, ou apenas protelar um processo falimentar.

É notório que a crise econômico-financeira das empresas listadas na pesquisa advém de fatores pontuais da economia brasileira, uma série de questões que não poderão ser solucionadas apenas com os meios disponibilizados na Lei 11.101/05 (BRASIL, 2005). Conclui-se, portanto, que não há efetivação da legislação brasileira no tocante ao incentivo da atividade econômica, sendo que a recuperação judicial representa, atualmente, em escala nacional, o único incentivo legislativo à preservação das empresas em crise econômico-financeira.

Essas questões são de interesse comum da sociedade. A geração de emprego e renda depende da boa saúde financeira, econômica e operacional das empresas; porém, estas também dependem de normas e regulamentos que agilizem os processos, quando suas situações não estiverem conforme o planejado. $\mathrm{O}$ que se percebe é uma morosidade do sistema judicial no despacho dos processos de recuperação judicial, o que pode deixar a empresa em um risco maior do que o atualmente vivido.

As limitações encontradas na realização desta pesquisa foram relativas ao período avaliado, pois, devido ao contexto socioeconômico peculiar de recessão no País, inibe o isolamento das causas da efetividade ou não do regime de recuperação judicial.

Assim, para estudos futuros, sugere-se um acompanhamento contínuo das empresas abordadas na pesquisa, com vistas a verificar o desfecho do desempenho econômico, financeiro e operacional de suas atividades, a fim de constatar quando e como irão se recuperar econômica e financeiramente, e se um dia alcançarão a almejada reestruturação.

\section{REFERÊNCIAS}

ABRÃO, Carlos Henrique; TOLEDO, Paulo F. C. de. Comentários à lei de recuperação de empresas e falência. 6. ed. São Paulo: Saraiva, 2016.

AKANIME, Carlos Takeo; YAMAMOTO, Roberto Katsuhiro. Estudo dirigido de estatística descritiva. 3 ed. São Paulo: Érica, 2013.

ASSAF NETO, Alexandre. Estrutura e análise de balanços: um enfoque econômico-financeiro. 9. ed. São Paulo: Atlas, 2010.

AYOUB, Luiz Roberto; CAVALLI, Cássio. FGV - A Construção Jurisprudencial da Recuperação Judicial de Empresas. 2. ed. Rio de Janeiro: Forense, 2016. Disponível em: https://integrada.minhabiblioteca.com.br. Acesso em: 20 out. 2016.

BRAGA, Hugo Rocha. Demonstrações contábeis: estruturação, análise e interpretação. 7. ed. São Paulo: Atlas, 2012.

BRASIL. Lei no 6.404, de 15 de dezembro de 1976. Dispõe sobre as Sociedades por Ações. Brasília, DF: Presidência da República, 1976. Disponível em: https://www.planalto.gov.br/ ccivil_03/leis/L6404consol.htm. Acesso em: 20 out. 2016.

BRASIL. Lei $\mathbf{n}^{\mathbf{0}} \mathbf{1 0 . 4 0 6}$, de 10 de janeiro de 2002. Institui o Código Civil. Brasília, DF: Presidência da República, 2002. Disponível em: http://www.planalto.gov.br/ccivil_03/ leis/2002/L10406.htm\#art2044. Acesso em: 20 out. 2016. 
BRASIL. Lei $\mathbf{n}^{\mathbf{0}}$ 11.101, de 9 de fevereiro de 2005. Regula a recuperação judicial, a extrajudicial e a falência do empresário e da sociedade empresária. Brasília, DF: Presidência da República, 2005. Disponível em: https://www.planalto.gov.br/ccivil_03/ato2004-2006/2005/ lei/111101.htm. Acesso em: 15 set. 2016.

BRASIL. Lei $\mathbf{n}^{\mathbf{0}} \mathbf{1 1 . 6 3 8}$, de 28 de dezembro de 2007. Altera e revoga dispositivos da Lei no 6.404, de 15 de dezembro de 1976, e da Lei no 6.385 , de 7 de dezembro de 1976, e estende às sociedades de grande porte disposições relativas à elaboração e divulgação de demonstrações financeiras. Brasília, DF: Presidência da República, 2007. Disponível em: http://www.planalto.gov.br/ccivil_03/_ato2007-2010/2007/lei/ 111638.htm. Acesso em: 16 out. 2016.

BRASIL. Lei $n^{0}$ 11.941, de 27 de maio de 2009. Altera a legislação tributária federal. Brasília, DF: Presidência da República, 2009. Disponível em: http://www.planalto.gov.br/ccivil_03/_ato2007-2010/2009/Lei/L11941.htm. Acesso em: 25 out. 2016.

CARTER, Richard; VAN AUKEN, Howard. Small Firm Bankruptcy. Journal of Small Business Management, v. 44, n. 4, p. 493-512, 2006.

COELHO, Fábio Ulhoa. Comentários à lei de falências e de recuperação de empresas. 10 . ed. São Paulo: Saraiva, 2014.

CORREÇÃO: 'Imprevisibilidade econômica' é base para renegociações. DCI - Diário Comércio Indústria \& Serviços, São Paulo, 28 nov. 2016. Disponível em: https://www.dci.com. br/economia/correc-o-imprevisibilidade-economica-e-base-para-renegociac-es-1.619452. Acesso em: 15 mar. 2019.

ECKERT, Alex. Teoria da contabilidade. 2. ed. São Paulo: Edipro, 2013.

FAZZIO JÚNIOR, Waldo. Lei de Falência e
Recuperação de Empresas. 7. ed. São Paulo: Atlas, 2015. Disponível em: https://integrada. minhabiblioteca.com.br. Acesso em: 30 set. 2016.

FRANCISCO FILHO, Valter Pereira. Finanças. 2015. Disponível em: https://ucs.bv3.digitalpages.com.br/users/publications. Acesso em: 30 set. 2016 .

GITMAN, Lawrence J.; ZUTTER, Chad J. Principles of Managerial Finance. London: Prentice Hall, 2010. Disponível em: http:// www.pearsonmiddleeastawe.com/pdfs/SAMPLE-managerial-finance.pdf. Acesso em: 7 nov. 2016.

GRIFFIN, Michael P. Contabilidade e finanças: série fundamentos. São Paulo: Saraiva, 2012. Disponível em: https://integrada.minhabiblioteca.com.br. Acesso em: 20 out. 2016.

LINS, Luiz Santos; FRANCISCO FILHO, José. fundamentos e análise das demonstrações contábeis: uma abordagem interativa. São Paulo: Atlas, 2012. Disponível em: https://integrada.minhabiblioteca.com.br. Acesso em: 2 out. 2016

MAMEDE, Gladston. Direito empresarial brasileiro: falência e recuperação de empresas. 8. ed. São Paulo: Atlas, 2016. v. 4. Disponível em: https://integrada.minhabiblioteca.com.br. Acesso em: 25 out. 2016.

MARTINS, Adriano de Oliveira. Recuperação de empresa em crise: a efetividade da autofalência no caso de inviabilidade da recuperação. Curitiba: Juruá, 2016.

MASCARENHAS, Sidnei A. (org.). Metodologia científica. São Paulo: Pearson, 2012. Disponível em: https:/ucsvirtual.ucs.br/startservico/PEA/. Acesso em: 10 jun. 2016.

MATARAZZO, Dante Carmine. Análise financeira de balanços: abordagem gerencial. 
7. ed. São Paulo: Atlas, 2010.

MICHEL, Maria Helena. Metodologia e pesquisa científica em ciências sociais: um guia prático para acompanhamento da disciplina e elaboração de trabalhos monográficos. 3. ed. São Paulo: Atlas, 2015. Disponível em: https:// integrada.minhabiblioteca.com.br. Acesso em: 4 out. 2016.

MONTOTO, Eugenio. Contabilidade geral e análise de balanços esquematizado. 3. ed. São Paulo: Saraiva, 2014. Disponível em: https://integrada.minhabiblioteca.com.br. Acesso em: 27 set. 2016.

PADOVEZE, Clóvis Luís; BENEDICTO, Gideon Carvalho de. Análise das demonstrações financeiras. 3. ed. São Paulo: Cengage Learning, 2011.

PEREIRA, José Matias. Manual de metodologia da pesquisa científica. 3. ed. São Paulo: Atlas, 2012. Disponível em: https://integrada. minhabiblioteca.com.br. Acesso em: 1 out. 2016.

QUINTANA, Alexandre Costa. Contabilidade básica. São Paulo: Saraiva, 2014. Disponível em: https://ucsvirtual.ucs.br/startservico/MIB/. Acesso em: 10 ago. 2015.

RAMOS, Albenides. Metodologia da pesquisa científica: como uma monografia pode abrir o horizonte do conhecimento. São Paulo: Atlas, 2009. Disponível em: https://integrada.minhabiblioteca.com.br. Acesso em: 4 out. 2016.

ROBERTS, S. J. et al. International secured transactions and insolvency. International Lawyer, v. 44, n. 1, p. 301-320, 2010.

SALOMÃO, Luis Felipe; SANTOS, Paulo Penalva. Recuperação judicial, extrajudicial e falência. 2. ed. Rio de Janeiro: Forense, 2015. Disponível em: https://integrada.minhabiblioteca.com.br. Acesso em: 30 set. 2016.
SAPORITO, Antônio. Análise e estruturação das demonstrações contábeis. Curitiba: Intersaberes, 2015. Disponível em: https://ucs.bv3. digitalpages.com.br/users/publications. Acesso em: 30 set. 2016.

SERASA EXPERIAN. Número de recuperações judiciais bate recorde histórico em 2015, revela Serasa Experian. Serasa Experian, São Paulo, 25 jul. 2016. Disponível em: http://noticias.serasaexperian.com.br/numero-de-recuperacoes-judiciais-bate-recorde-historico-em-2015-revela-serasa-experian/. Acesso em: 25 jul. 2016.

SERASA EXPERIAN. Recuperações judiciais batem recorde histórico em 2016, revela Serasa Experian. Serasa Experian, São Paulo, 28 fev. 2017. Disponível em: http://noticias.serasaexperian.com.br/blog/2017/01/12/ comercio-industria-e-servicos-batem-recorde-de-pedidos-de-recuperacao-judicial-em-2016-mostra-serasa-experian/. Acesso em: 28 fev. 2017.

SILVA, Alexandre Alcântara da. Estrutura, análise e interpretação das demonstrações contábeis. 3. ed. São Paulo: Atlas, 2012.

SIQUEIRA, Marli Aparecida da Silva. Monografias e teses: das normas técnicas ao projeto de pesquisa: teoria e prática. 2. ed. Brasília: Consulex, 2013. Disponível em: https://integrada.minhabiblioteca.com.br. Acesso em: 1 out. 2016.

TOLEDO, Paulo Fernando Campos Salles de; ABRÃO, Carlos Henrique (coord.). Comentários à lei de recuperação de empresas e falência. 5. ed. São Paulo: Saraiva, 2012.

VICECONTI, Paulo Eduardo Vilchez; NEVES, Silvério das. Contabilidade básica. 16. ed. São Paulo: Saraiva, 2013. Disponível em: https://integrada.minhabiblioteca.com.br. Acesso em: 2 out. 2016. 